UDC 343.2:343.23

LBC 67.308.1

\title{
DOES THE RUSSIAN LAW NEED THE CATEGORY OF PUBLIC DANGER? ${ }^{1}$
}

\author{
Alexey P. Rozhnov \\ Volgograd State University, Volgograd, Russian Federation
}

\begin{abstract}
Introduction: the article deals with the problem of whether the phenomenon of "crime" has the feature of public danger as its significant dominant, and also the presence of this feature in other (non-criminal) offences prohibited by the other (non-criminal) branches of the Russian law. The goals and objectives of the research are the analysis of the category of "public danger", the disclosure of its social nature and legal gist. The research methods are the methods of scientific analysis which are traditional for the humanities. Results: the paper analyzes the opinions of the scientists proposing to abandon the use of the term "public danger", as well as the opinions of those authors who deny the universal interdisciplinary nature of public danger, insisting on its specificity exclusively for crimes. It is emphasized that the possible elimination of "public danger" will dilute the criteria for criminal and non-criminal acts, will make the violence by the state in the field of response to law-violating behavior illegitimate and unjust. In turn, the assumption of lack of the feature of public danger in all offenses will dilute the unified social nature of this kind of human behavior and allow arbitrarily setting and applying sanctions of the public branches of the domestic law. Scope of application: this article is primarily intended for the use in the legislative activities and scientific work. It is concluded that public danger is expressed in violating or creating a danger of violating the values shared, protected and cultivated by the society. In this regard, public danger is both the dominant feature of a crime, its essential sign, and a universal cross-sectoral category because of its specificity for all types of infringing conduct.
\end{abstract}

Key words: public danger, crime, offense, criminalization of acts, social harm.

УДК 343.2:343.23

ББК 67.308 .1

\section{НУЖНА ЛИ РОССИЙСКОМУ ПРАВУ КАТЕГОРИЯ ОБЩЕСТВЕННОЙ ОПАСНОСТИ? ${ }^{1}$}

\author{
Алексей Петрович Рожнов \\ Волгоградский государственный университет, г. Волгоград, Российская Федерация
}

Введение: в статье рассматриваются проблемы наличия у явления «преступления» свойства общественной опасности как его ведущего, существенного признака, а также наличия данного свойства у иных (непреступных) правонарушений, запрещенных иными (неуголовными) отраслями российского права. Целями и задачами исследования выступает анализ категории «общественная опасность», раскрытие ее социальной природы и правовой сущности. Методами исследования выступают традиционные для гуманитарного знания методы научного анализа. Результаты: в работе проанализированы позиции ученых, предлагающих отказаться от использования термина «общественная опасность», а равно и мнения тех авторов, которые отрицают универсальный межотраслевой характер общественной опасности, настаивая на ее характерности исключительно для преступлений. Обращается внимание, что возможный отказ от общественной опасности размоет критерии преступного и непреступного, сделает нелегитимным и несправедливым государственное насилие в области реакции на правонарушающее поведение. В свою очередь допущение отсутствия свойства общественной опасности у всех правонарушений «размоет» единую социальную природу такого рода человеческого поведения, позволит произвольно устанавливать и применять санкции публичных отраслей отечественного права. Область применения: статья предназначена прежде всего для использования в законотворческой деятельности и в научной работе. Делается вывод о том, что общественная опас- 
ность выражается в нарушении или создании угрозы нарушения разделяемых, защищаемых, культивируемых обществом ценностей. В этой связи общественная опасность является как ведущим свойством преступления, его существенным признаком, так и универсальной межотраслевой категорией в силу ее характерности для всех видов правонарушающего поведения.

Ключевые слова: общественная опасность, преступление, правонарушение, криминализация деяний, социальная вредность.

\section{Введение}

Согласно законодательной дефиниции (ч. 1 ст. 14 УК РФ) преступлением признается «виновно совершенное общественно опасное деяние, запрещенное настоящим Кодексом под угрозой наказания». Основываясь на данном определении, учеными выводятся два главных признака преступления - общественная опасность и противоправность, которые принято именовать соответственно материальным и формальным.

Заметим, что необходимость сохранения признака общественной опасности в ныне действующем УК была предметом острой полемики. Так, довольно солидная группа российских криминалистов в период обсуждения в начале 1990-х гг. различных проектов Кодекса предлагала сосредоточить внимание в законодательном определении преступления только на формальном признаке, отказавшись от материального признака вообще из-за его политизированности и декларативности [5, с. 63].

Тем не менее в принятом в 1996 г. Государственной Думой РФ Уголовном кодексе признак общественной опасности в дефиниции преступления сохранился, хотя и без раскрытия его содержания в тексте Кодекса. Такое правотворческое решение можно объяснить исключительно несформированностью в обществе на момент принятия Кодекса тех ценностей, которые должен охранять уголовный закон.

Помимо УК законодательное определение отраслевого правонарушения содержится в ч. 1 ст. 2.1 КоАП РФ и в ст. 106 Налогового кодекса РФ. Нетрудно, однако, увидеть, что при определении понятий административного и налогового правонарушений правотворец акцентирует внимание на запрещенности деяния законом, не пытаясь при этом объяснить, почему данное деяние должно быть запрещено нормами позитивного права.

Таким образом, определение понятия преступления в ч. 1 ст. 14 УК РФ, указываю- щее на его общественную опасность, выглядит некоторым диссонансом, что тем более актуализирует вопрос о сущности общественной опасности и ее роли как в сфере конструирования закона, так и в области властной правореализации.

\section{Общественная опасность как критерий легитимности уголовного закона}

Сохранение в действующем УК указания на общественную опасность преступления необходимо признать правильным, потому что одна лишь только запрещенность не способна объяснить, почему те или иные деяния были признаны или могут быть признаны преступлениями.

Уголовное право - зона организованного насилия, представляющая собой наиболее сильную реакцию публичной власти на определенные виды поведения. От того, адекватна ли эта реакция содеянному, соотносится ли она с тяжестью типизированного поведения человека, за конкретные проявления которого она следует, напрямую зависит вопрос о легитимности уголовного закона. Таким образом, четкие критерии определения оснований наступления наиболее суровой государственной реакции на некоторые виды поведения человека, отвечающие интересам и представлениям общества, легитимизируют государственное насилие и делают его справедливым, а потому и правовым. Поэтому правы те авторы, которые определяют общественную опасность как главный признак преступления и одновременно его внутреннее свойство, раскрывающее его социальную сущность [1, с. 131].

Свое выражение анализируемое свойство преступления находит и в принципе справедливости (ст. 6 УК), предписывающем законодателю возводить в ранг наказуемых только те деяния, которые должны обладать значительной долей общественной опасности для 
охраняемых правом интересов. Отступление законодателя от принципа справедливости может проявляться либо в игнорировании объективно опасных видов поведения, либо же в запрещении поступков, не являющихся в действительности опасными с точки зрения сложившихся в обществе представлений о должном и порицаемом.

\section{Общественная опасность}

\section{как универсальное свойство правонарушения}

Определяя любое правонарушение, представители теории права указывают на такую его универсальную черту, как способность наносить вред обществу. Дифференциация правонарушений на виды происходит в основном по «степени их вредности и опасности для общественных отношений» [2, с. 580, 584], обусловливая выделение проступков и преступлений, что закономерно ставит ряд вопросов: является ли общественная опасность синонимом социальной вредности или же общественная опасность - это характерное свойство только преступных посягательств, а потому она же - особый измеритель социальной вредности в преступлении?

Названные вопросы отнюдь не новы и были поставлены еще советскими криминалистами. Как полагал, например, Н.Д. Дурманов, преступление существенно отличается от иных проступков по характеру причиняемого вреда, почему общественная опасность характерна только для преступлений. Непреступные правонарушения неспособны принести вред всей системе общественных отношений и в этом смысле стать общественно опасными [1, с. 135].

Настаивая на общественной опасности как специфической черте преступления, А.И. Марцев предложил ввести категорию «общественная вредность», присущую всем правонарушениям, степень которой позволяет провести их дифференциацию. Применительно к преступлению общественная вредность заключается в тех последствиях, которые причиняются конкретным преступлением как единичным социальным явлением. Сущность же общественной опасности заключается в том, что «преступное поведение или деятельность, об- ладая свойствами прецедента, создает угрозу повторения подобных преступлений в будущем» [3, с. 149]. Таким образом, чрезвычайная степень общественной вредности у преступлений и «порождает новое качество - общественную опасность, лежащую, однако, за пределами общественной вредности как таковой, поскольку сама вредность при этом выступает только предпосылкой появления общественной опасности» [3, с. 155].

Возражая Н.Д. Дурманову, А.А. Пионтковский указывал, что «различие между преступлением и дисциплинарным или административным проступком заключается в степени их общественной опасности», которая и обусловливает переход количества в качество [4, c. 41].

Последняя точка зрения представляется наиболее предпочтительной, поскольку исходит из правильного понимания единой социальной природы правонарушения и преступления, из соотношения этих категорий как рода и вида. Предположение иного размывает границы понятия правонарушения, искусственно делает преступление особым правовым явлением, выводя его за рамки правонарушающего поведения, допускает произвольное применение санкций норм публичных отраслей права, фактически означает возможность произвольного установления иной (неуголовной) ответственности в отсутствие действительной вредоносности того или иного поведения.

Указывая, наконец, что иные деликты не способны нанести вред всей системе общественных отношений, в отличие от преступления, сторонники данной позиции не учитывают того, что, объявляя наказуемым определенный вид человеческого поведения, государство исходит из его потенциальной опасности для основ существования общества, из его опасности на будущее время, из угрозы его превращения в массовидное поведение. Поэтому угроза дестабилизации существования общества побуждает запрещать как проступки, так и преступления, поскольку и те и другие в главном своем качестве одинаково опасны для общества. Отличие же между преступлениями и иными правонарушениями происходит не по свойству их возможного влияния на стабильность социальных связей, а по степени и скорости их воздействия на эти свя- 
зи. Отсюда и преступления, и проступки, и даже некоторые поступки, не запрещенные правом, обладают общественной опасностью, отличаясь друг от друга лишь только степенью своего отрицательного влияния на стабильность общественной жизни.

Принципиально соглашаясь с А.И. Марцевым в его подходе к дифференциации правонарушений по степени их (в его терминологии) общественной вредности, нельзя поддержать автора в том, что якобы только преступления, будучи угрозой повторения их в будущем, создают опасность для общества, а потому являются общественно опасными. Думается, любой деликт в сфере права, единожды став прецедентом, создает угрозу своего многократного повторения. И, более того, опасными для общества являются не только преступления и деликты, но даже и девиации (пьянство, наркомания, проституция и пр.), многие из которых, будучи только аморальным поведением, успешно встраиваются в систему причин и условий преступности и обусловливают еe.

Наконец, будучи важнейшим социальным свойством преступления, общественная опасность объективна, то есть не зависит от ее правовой оценки законом. Отсюда становится непонятным, почему именно преступное поведение, создавая угрозу его многократного повторения в будущем, тем самым опасно для общества? При таком подходе как раз более опасно не запрещенное законом социально вредное деяние, поскольку вероятность его повторения гораздо выше. Следовательно, отказывать ему в свойстве общественной опасности нет никаких серьезных оснований.

\section{Выводы}

1. Общественная опасность является ведущей чертой преступления, в связи с чем ее употребление в законодательном понятии преступления (ч. 1 ст. 14 УК РФ) представляется уместным, тогда как и ее же отсутствие в законодательных дефинициях иных отраслевых правонарушений (ч. 1 ст. 2.1 КоАП РФ, ст. 106 Налогового кодекса РФ) является серьезным правотворческим недостатком.

2. Общественная опасность выражается в нарушении или создании угрозы наруше- ния разделяемых обществом ценностей, поэтому ее адекватное отражение в уголовном и иных законах в виде объявления правонарушающими и порицаемыми типизированных массовидных поступков людей является гарантией справедливости применения мер уголовной репрессии и иных форм принудительного государственного воздействия за преступления и иные правонарушения.

3. Общественная опасность является универсальным сущностным свойством (признаком) любого правонарушения, так как отражает социальную непереносимость тех или иных видов человеческого поведения и ожидание со стороны большинства членов общества организованной государственной реакции на такие поведенческие акты, заключающейся в объявлении их запрещенными и наказуемыми.

\section{ПРИМЕЧАНИЯ}

${ }^{1}$ Статья подготовлена при поддержке гранта Российского гуманитарного научного фонда. Проект № 17-03-00720.

${ }^{2}$ См. работу: Уголовное уложение вместо УК РФ / Г. В. Дашков [и др.] (цит. по: [5]).

\section{СПИСОК ЛИТЕРАТУРЫ}

1. Дурманов, Н. Д. Понятие преступления / Н. Д. Дурманов. - М. : Изд-во АНСССР, 1948. - 315 с.

2. Комаров, С. А. Правонарушение / С. А. Комаров // Общая теория государства и права : акад. курс. В 2 т. Т. 2 / под ред. проф. М. Н. Марченко. М. : Зерцало, 1998. - Гл. XXVII. - С. 580-591.

3. Марцев, А. И. Общественная вредность и опасность преступления / А. И. Марцев // Известия высших учебных заведений. Серия «Правоведение». - 2001. - № 4 (237). - С. 148-155.

4. Пионтковский, А. А. Курс советского уголовного права. В 6 т. Т. 2 / А. А. Пионтковский. М. : Наука, 1970. -516 с.

5. Признаки (свойства) преступления // Энциклопедия уголовного права. Т. 3 : Понятие преступления. - СПб. : Изд. проф. Малинина, 2005. Гл. 2. - С. 47-109.

\section{REFERENCES}

1. Durmanov N.D. Ponyatie prestupleniya [The Concept of Crime]. Moscow, Izd-vo Akademii nauk SSSR, 1948. $315 \mathrm{p}$. 
2. Komarov S.A. Pravonarusheniye (glava XXVII) [Legal Offense (Chapter XXVII)]. Marchenko M.N., ed. Obshchaya teoriya gosudarstva i prava. Akademicheskiy kurs v 2-kh t. T. 2: Teoriya prava [The General Theory of State and Law. Academic Course in 2 vols. Vol. 2: Theory ofLaw]. Moscow, Zertsalo Publ., 1998, pp. 580-591.

3. Martsev A.I. Obshchestvennaya vrednost i opasnost prestupleniya [Public Harm and the Danger of Crime]. Izvestiya vysshikh uchebnykh zavedeniy. Seriya «Pravovedenie», 2001, no. 4 (237), pp. 148-155.
4. Piontkovskiy A.A. Kurs sovetskogo ugolovnogo prava. V 6 t. T. 2 [The Course of Soviet Criminal Law. In 6 vols. Vol. 2]. Moscow, Nauka Publ., 1970.516p.

5. Priznaki (svoystva) prestupleniya [Signs (Properties) of the Crime]. Entsiklopediya ugolovnogo prava. T. 3: Ponyatie prestupleniya [Encyclopedia of the Criminal Law. Vol. 3: The Concept of Crime]. Saint Petersburg, Prof. Malinina Publ., 2005, Ch. 2, pp. 47-109.

\section{Information about the Author}

Alexey P. Rozhnov, Candidate of Juridical Sciences, Associate Professor, Department of Criminal Law, Volgograd State University, Prosp. Universitetsky, 100, 400062 Volgograd, Russian Federation, rozhnov@volsu.ru.

\section{Информация об авторе}

Алексей Петрович Рожнов, кандидат юридических наук, доцент кафедры уголовного права, Волгоградский государственный университет, просп. Университетский, 100, 400062 г. Волгоград, Российская Федерация, rozhnov@volsu.ru. 